\title{
The Propagation of Symmetric Lamb Wave in the Hollow Cylinder
}

\author{
Yu. V. Myshkin ${ }^{1,2}$, O. V. Murav'eva ${ }^{1,3}$, A. A. Fotina ${ }^{1}$, \\ T. S. Chukhlanceva ${ }^{1}$ \\ ${ }^{1}$ Department of Instruments and Techniques of Measurement, Testing, Diagnostics, \\ Kalashnikov Izhevsk State Technical University, Izhevsk, Russian Federation \\ ${ }^{2}$ IntroScan Technology JSC, Chaykovsky, Perm Krai, Russian Federation \\ ${ }^{3}$ Udmurt Federal Research Center of Ural Branch of Russian Academy of Sciences, \\ Izhevsk, Russian Federation \\ E-mail: ${ }^{1}$ mubm@yandex.ru \\ Received: September 06, 2019
}

\begin{abstract}
The article presents studies of the propagation velocity of the symmetric Lamb wave in a pipe with a diameter of $247 \mathrm{~mm}$ and a wall thickness of $8.4 \mathrm{~mm}$. Studies include finite element modeling of the wave propagation process and an experiment using piezoelectric transducers with dry point contact based on sounding $600 \mathrm{~mm}$ of pipe at a frequency of $50 \mathrm{kHz}$. Plots of displacement components at wave propagation in the axial and circumferential directions are obtained, which show the prevalence of the longitudinal component over the vertical shear component from 6 to 30 times. The difference in the wave velocity at its propagation in the axial and circumferential directions was established, which amounted to $290 \mathrm{~m} / \mathrm{s}$. The simulation results are in satisfactory agreement with the experimental data.
\end{abstract}

Keywords: Lamb wave, hollow cylinder, wave velocity, finite element method, dry point contact, guided wave testing, geometric dispersion.

\section{INTRODUCTION}

In acoustic waveguide testing, guided waves propagating along the products are used: Pochhammer, Lamb, SH-waves [1-9]. Typically, these types of waves used in the low frequency range, are capable of traveling up to $200 \mathrm{~m}$ from the point of excitation, and do not require scanning $[5,9]$. Linearly extended objects (rails, rods, pipes, etc.) [1-6] and flat products limited by the environment (plates, sheets, films, etc.) [9-13] can be used as testing products.

From literary sources $[5,8,9]$ it is known that from the fundamental modes of guided waves, the symmetric Lamb wave has one and a half times less attenuation compared to the SH wave and three times as compared to the antisymmetric Lamb wave. In addition, the use of the symmetric Lamb wave makes it possible to detect longitudinally oriented defects whose dimensions are comparable to the wavelength, and in the case of using the multiple reflection method, with dimensions by an order of magnitude less than the wavelength. Nevertheless,

(C) Yu. V. Myshkin, O. V. Murav’eva, A. A. Fotina, T. S. Chukhlanceva, 2019 
the symmetrical Lamb wave is less sensitive to defects in comparison with other types of waves at a given frequency $[1-5,8]$.

As a rule, Lamb waves are used in the frequency range with a low dispersion of the excited mode. For this, dispersion curves are calculated for the modes of the desired wave types using specialized software $[5,9,11,13-15]$. Accounting for velocity dispersion allows to decipher the patterns of received signals, conduct thickness measurement of the studied products and limit the frequency range at nondestructive testing. The most commonly used modes for flaw detection of pipelines and plates, $\mathrm{S} 0$ and $\mathrm{L}(0,2)$ in the region of minimal dispersion, allow detecting corrosion defects, cracks, dents, etc. [10-14, 16, 17]

It is known that the main quantities that determine the dispersion of velocity are the geometric dimensions of the product, properties and parameters of the material structure [9]. Given the uniformity of these properties, the velocity can be calculated quite accurately using dispersion curves. Inhomogeneity in the geometry and properties of the material [18-19] as well as defects lead to an additional change in the propagation velocity of guided waves. As such an inhomogeneity, the cylindrical surface of a hollow cylinder can be considered as a special case of a plate with a curved surface, and the phenomenon of a change in velocity on geometric inhomogeneities is called geometric dispersion.

The main studies in the field of guided wave propagation are related to the influence of bends and complex pipe geometry $[15,20]$, alternative methods of wave excitation and reception [16, 21-23], their use in tomography systems [17, 24], development of systems for excitation and receiving waves in circumferential direction of the pipe [16, 22-23, 25-28], the possibilities of increasing sensitivity due to wave focusing technique [7, 29], the influence of defects on mode conversion [14, 23, 27], the possibilities of implementing excitation and reception of various modes and types of waves [29-33]. In most works, with the exception of Viktorov's works for a surface wave [34], there is no information on the difference in the propagation velocity of guided waves in the axial and circumferential directions on a cylindrical surface, which can be significant for a small diameter and a large wall thickness of pipe.

The article presents studies of the geometric dispersion of the propagation velocity of the symmetric Lamb wave in a hollow steel cylinder with an external diameter of $247 \mathrm{~mm}$ and a wall thickness of $8.4 \mathrm{~mm}$ at a frequency of $200 \mathrm{kHz}$ and a sounding base of $300 \mathrm{~mm}$.

\section{DISPERSION CURVES}

The main characteristic of guided waves is the velocity dispersion, which can be calculated using the Pochhammer-Chree dispersion equations. Figure 1 shows the dispersion curves calculated for a plate and a hollow cylinder in the Elastic Waveguide Tracer software product. As input parameters for the calculation, the geometric dimensions of the products (plate and pipe), its elastic and physical properties, presented in table 1 , were used.

From the presented dependences, one can establish the existence of lower symmetric S0, $\mathrm{S} 1$ and antisymmetric A0, A1 modes of the Lamb wave and the horizontally polarized shear wave SH0 in the frequency range up to $300 \mathrm{kHz}$. In the hollow cylinder at the same frequencies, there must exist longitudinal $\mathrm{L}(0,1), \mathrm{L}(0,2)$, flexural $\mathrm{F}(1, \mathrm{~m}), \mathrm{F}(\mathrm{n}, 1)$ and torsional $\mathrm{T}(0,1)$ waves.

At the operating frequency of $50 \mathrm{kHz}$ of the transducer used in this work, fundamental symmetric S0, antisymmetric A0 Lamb wave, and the horizontally polarized shear wave SH0 are excited. In this case, longitudinal $\mathrm{L}(0,1), \mathrm{L}(0,2)$, flexural $\mathrm{F}(1, \mathrm{~m}), \mathrm{F}(\mathrm{n}, 1)$ and torsional $\mathrm{T}(0,1)$ waves are excited in the pipe, the velocity of which is comparable to the velocity of the Lamb waves and the SH-wave. The calculated velocities for these modes are presented in table 2 . 
To excite the symmetric Lamb wave, one main component of the displacements is required, which is directed along the wave propagation, while a horizontally polarized shear wave will propagate in the perpendicular direction and possessing all three components of the antisymmetric Lamb wave will propagate in all directions.

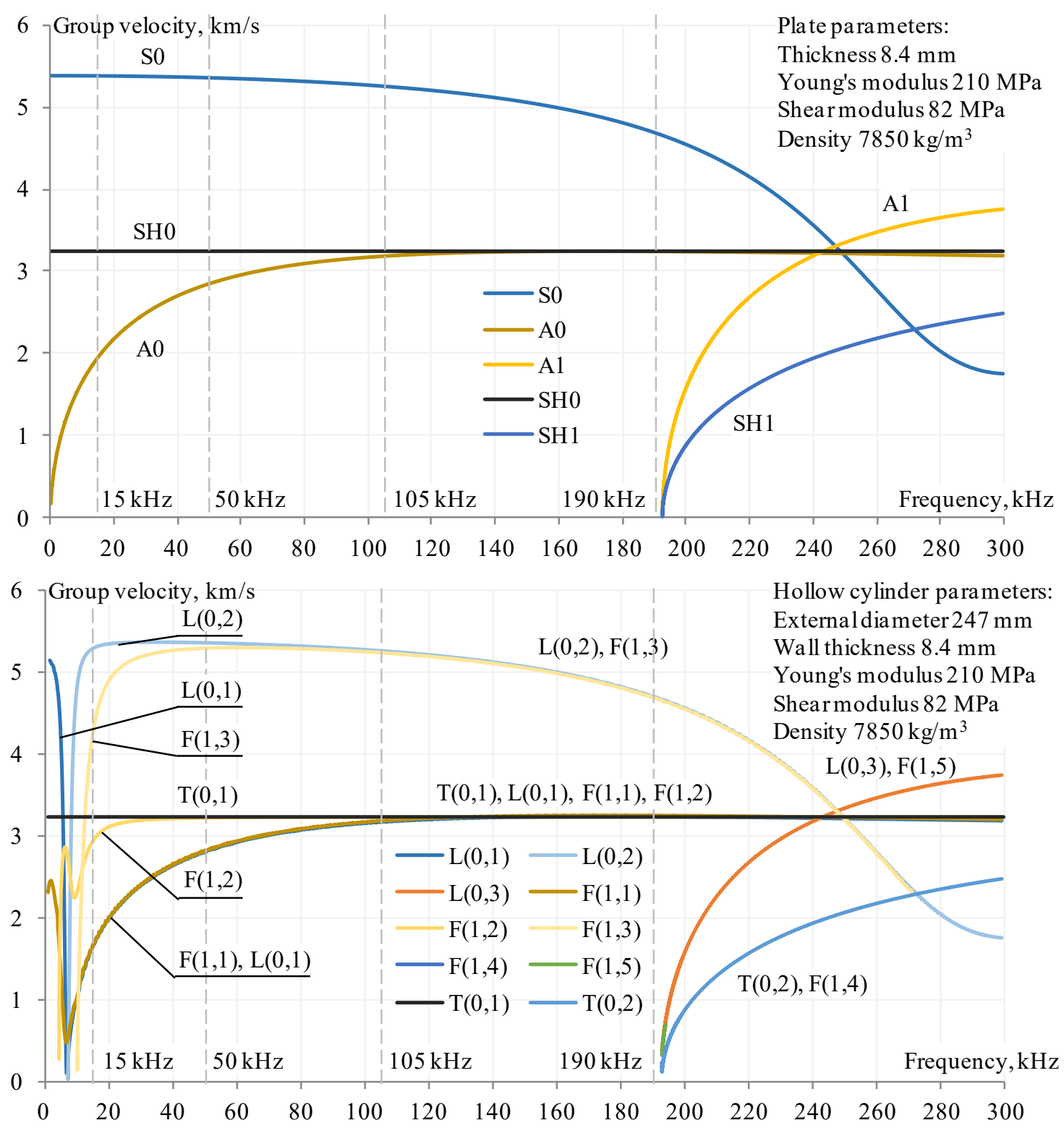

Figure 1. Dispersion curves of group velocities in a steel plate (a) and an steel hollow cylinder (b): $\mathrm{S}$ symmetrical mode of Lamb wave, A - antisymmetrical mode of Lamb wave, SH - horizontally polarized shear wave, $\mathrm{L}$ - longitudinal wave, $\mathrm{F}$ - flexural wave, $\mathrm{T}$ - torsional wave

Table 1. Geometric and material properties

\begin{tabular}{l|c|c|l|c|c}
\hline \multicolumn{1}{c|}{ Parameter } & Value & Dimension & \multicolumn{1}{|c|}{ Parameter } & Value & Dimension \\
\hline External radius & 123.5 & $\mathrm{~mm}$ & Shear modulus, $G$ & 82 & $\mathrm{GPa}$ \\
Wall thickness & 8.4 & $\mathrm{~mm}$ & Poisson's ratio, $\eta$ & 0.28 & - \\
Internal radius & 115.1 & $\mathrm{~mm}$ & Shear wave velocity, $C$ & 3232 & $\mathrm{~m} / \mathrm{s}$ \\
Young's modulus, $E$ & 210 & $\mathrm{GPa}$ & Density, $\rho$ & 7850 & $\mathrm{~kg} / \mathrm{m}^{3}$ \\
\hline
\end{tabular}




\begin{tabular}{c|c|c|c}
\hline \multicolumn{4}{|c}{ Table 2. Group velocities at the frequency of $50 \mathrm{kHz}$} \\
\hline Mode in plate & Group velocity (m/s) & Mode in pipe & Group velocity (m/s) \\
\hline A0 & 2825 & $\mathrm{~F}(1,1), \mathrm{F}(1,2), \mathrm{F}(1,3)$ & $2778,5300,3218$ \\
S0 & 5365 & $\mathrm{~L}(0,1), \mathrm{L}(0,2)$ & 2785,5362 \\
SH0 & 3242 & $\mathrm{~T}(0,1)$ & 3232 \\
\hline
\end{tabular}

\section{Finite ELEMENT PREDiCTION}

The model for studying the propagation of the symmetric Lamb wave (Figure 2) included a pipe section with length of $1 \mathrm{~m}$, an external diameter of $246.7 \mathrm{~mm}$ and an average wall thickness of $8.4 \mathrm{~mm}$. The geometric parameters, as well as the elastic and physical properties of the pipe material are presented in table 3 .
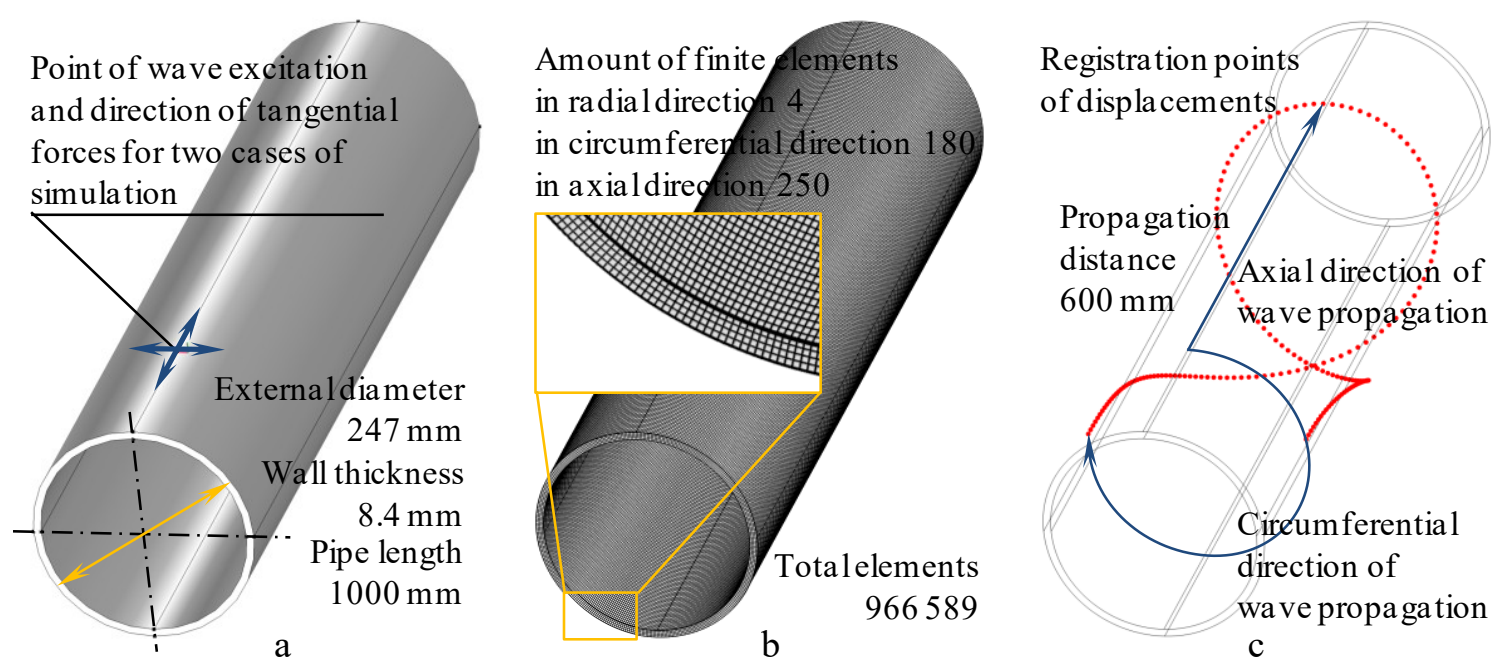

Figure 2. 3D model of the pipe (a), finite element mesh (b) and locations of registrations points (c): pipe length $1.0 \mathrm{~m}$, point of application of tangential force is located at a distance of $0.2 \mathrm{~m}$ from the pipe end

Table 3. Model parameters and properties

\begin{tabular}{l|c|c|c|c|c}
\hline \multicolumn{1}{c|}{ Parameter } & Value & Dimension & Parameter & Value & Dimension \\
\hline Poisson's ratio, $\eta$ & 0.281 & - & $\begin{array}{c}\text { External diameter } \\
\text { of cylinder, } D_{\text {ext }} \\
\text { Internal diameter } \\
\text { of cylinder, } D_{\text {int }}\end{array}$ & 246.7 & 229.9 \\
Shear wave velocity, $C$ & 3250 & $\mathrm{~m} / \mathrm{s}$ & $\mathrm{mm}$ \\
Density, $\rho$ & 7850 & $\mathrm{~kg} / \mathrm{m}^{3}$ & Cylinder length, $L$ & 1000 & $\mathrm{~mm}$ \\
Shear modulus, $G$ & $\rho C^{2}=82.9$ & $\mathrm{GPa}$ & Frequency, $f$ & 50 & $\mathrm{kHz}$ \\
Young's modulus, $E$ & $2 G(1+\eta)=212.4$ & $\mathrm{GPa}$ & Time step, $\Delta t$ & 100 & $\mathrm{~ns}$ \\
\hline
\end{tabular}

The boundary condition Point Load was applied at a distance of $200 \mathrm{~mm}$ from the pipe end at a point on the external cylindrical surface in the form of a tangential force action, the direction of which was specified in two ways: in the axial and circumferential directions. The shape of tangential force is shown in Figure 3.

Elastic oscillations were recorded at a distance of $600 \mathrm{~mm}$ from the point of excitation at angles of 0-360 degrees in increments of 1 degree relative to the generatrix of the pipe, taking 
into account displacements corresponding to the wave oscillation plot. As an example, Figure 4 shows the recorded oscillations when the wave propagation path deviates from the generatrix of the pipe by 20 degrees. The result shows the signals of the direct symmetric Lamb wave and reflected from the pipe end, merging with the through signal of the symmetric Lamb wave, and the through signal of the horizontally polarized shear wave.

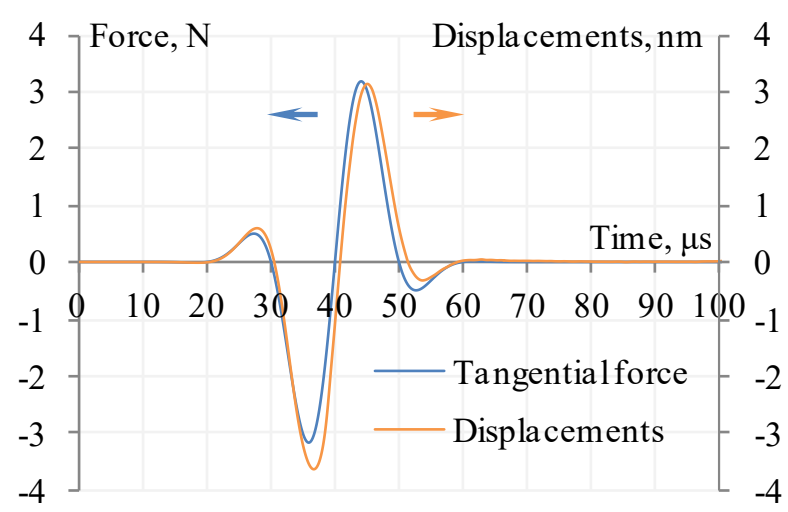

Figure 3. Pulse of the tangential force action and the shape of the elastic displacements pulse (calculated in the program): arrows indicate the correspondence of the graphs to the axes

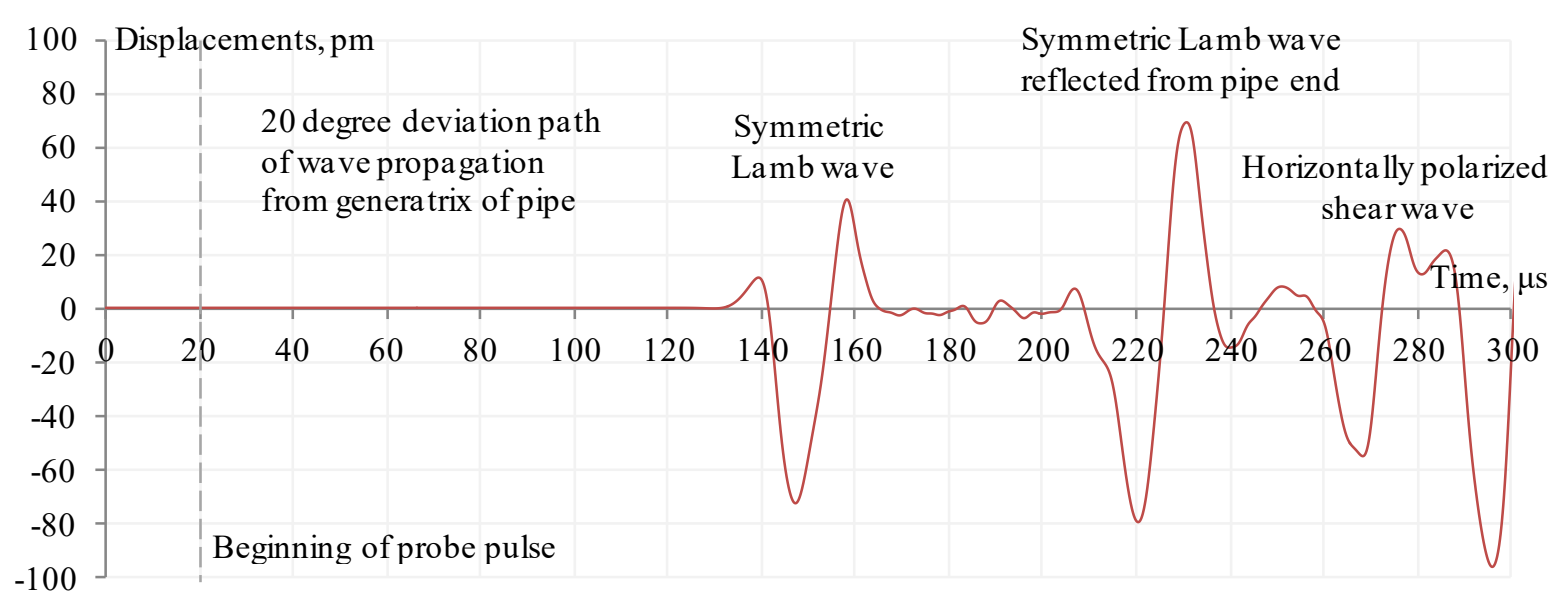

Figure 4. The signal received at a point at a distance of $600 \mathrm{~mm}$ from the excitation point when the wave propagation path deviates from the generatrix of the pipe by 20 degrees

The model was divided into finite elements based on the criterion of the minimum number of elements per wavelength necessary to obtain a satisfactory simulation result, which should be at least 4 . Thus, taking into account the calculated value of the propagation velocity of the symmetric Lamb wave, the maximum size of the finite elements was $4 \mathrm{~mm}$, and their total number according to the results of meshing is 966589 .

The time step was selected based on the Courant-Friedrichs-Levy criterion with a parameter for solving the wave equations of 0.1 and amounted to $20 \mathrm{~ns}$. Thus, taking into account the distance traveled by the wave, the total number of iteration steps in time was 3076.

The simulation results in the form of a distribution of the axial component of displacements at a time of $50 \mu \mathrm{s}$ and then with a step of $50 \mu \mathrm{s}$ are presented in Figure 5. The distributions also show a symmetric Lamb wave and the SH wave propagating in mutually perpendicular directions. 
The directions of displacements in the symmetric Lamb wave at its propagation in the axial and circumferential directions are presented in Figure 6 and Figure 7, respectively. In addition to the main axial component, the wave has a radial component that reaches its maximum at the moment of the change of the oscillation phase. A similar character of the oscillations is observed on the displacement diagrams (Figure 8) obtained at the moment of maximum displacements in the wave, at the moment of the phase change of the oscillations, and the average value of the displacements over the wave period. In this case, the ratio of the longitudinal component of the displacements to the vertical shear component is the greater, the closer the wave propagation path to the generatrix of the pipe, which varies from 6 to 30 .

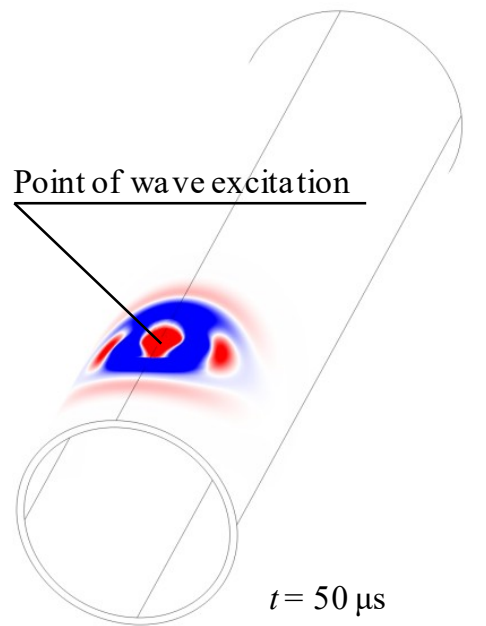

a

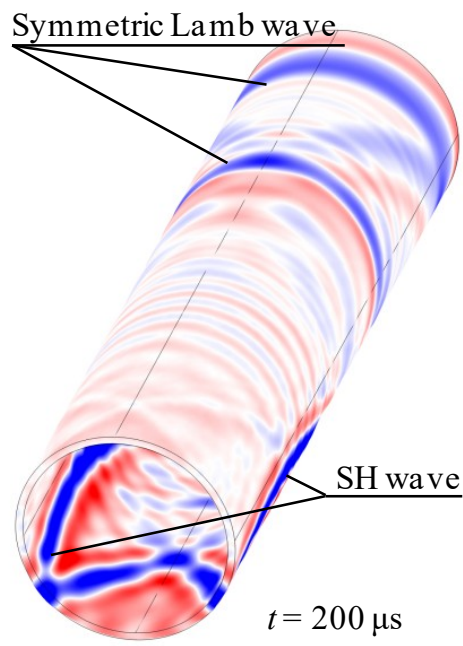

d

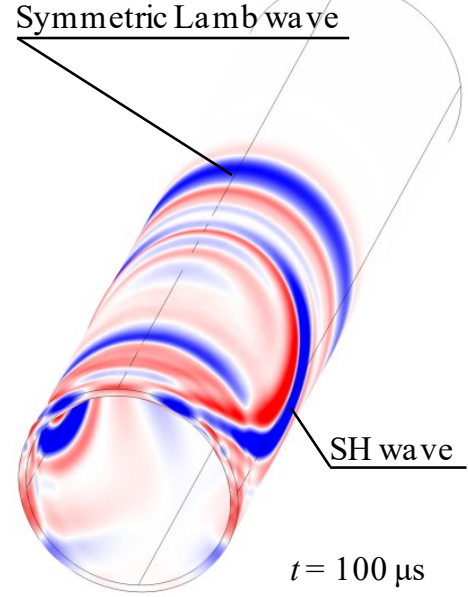

b

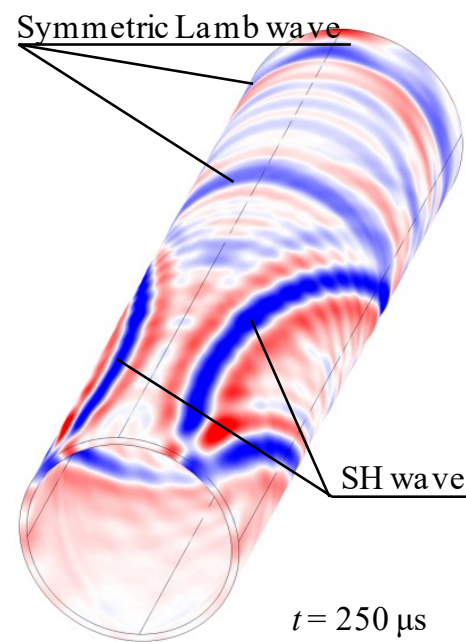

e

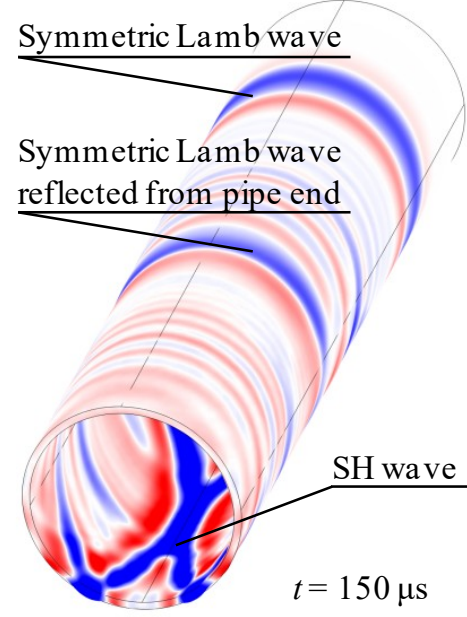

c

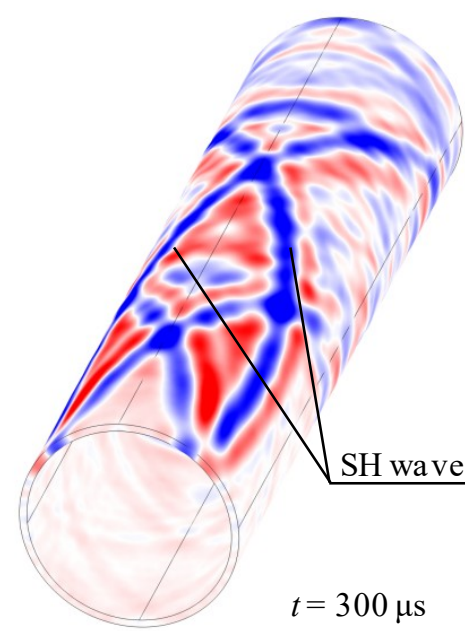

f

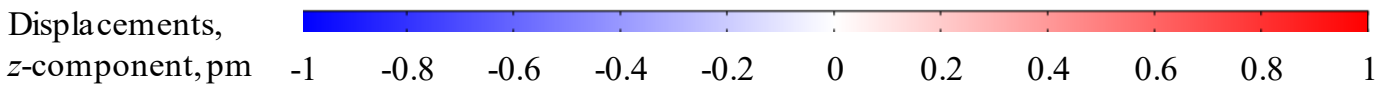

Figure 5. Distribution of displacements on the surface of the pipe at different points in time, $t=50 \mu \mathrm{s}$ (a), $t=100 \mu \mathrm{s}$ (b), $t=150 \mu \mathrm{s}$ (c), $t=200 \mu \mathrm{s}$ (d), $t=250 \mu \mathrm{s}$ (e), $t=300 \mu \mathrm{s}$ (f): light wave graduation is used, the dark blue color corresponds to the maximum negative displacements, the dark red corresponds to the maximum positive displacements (approximately $50 \mathrm{pm}$ ) 

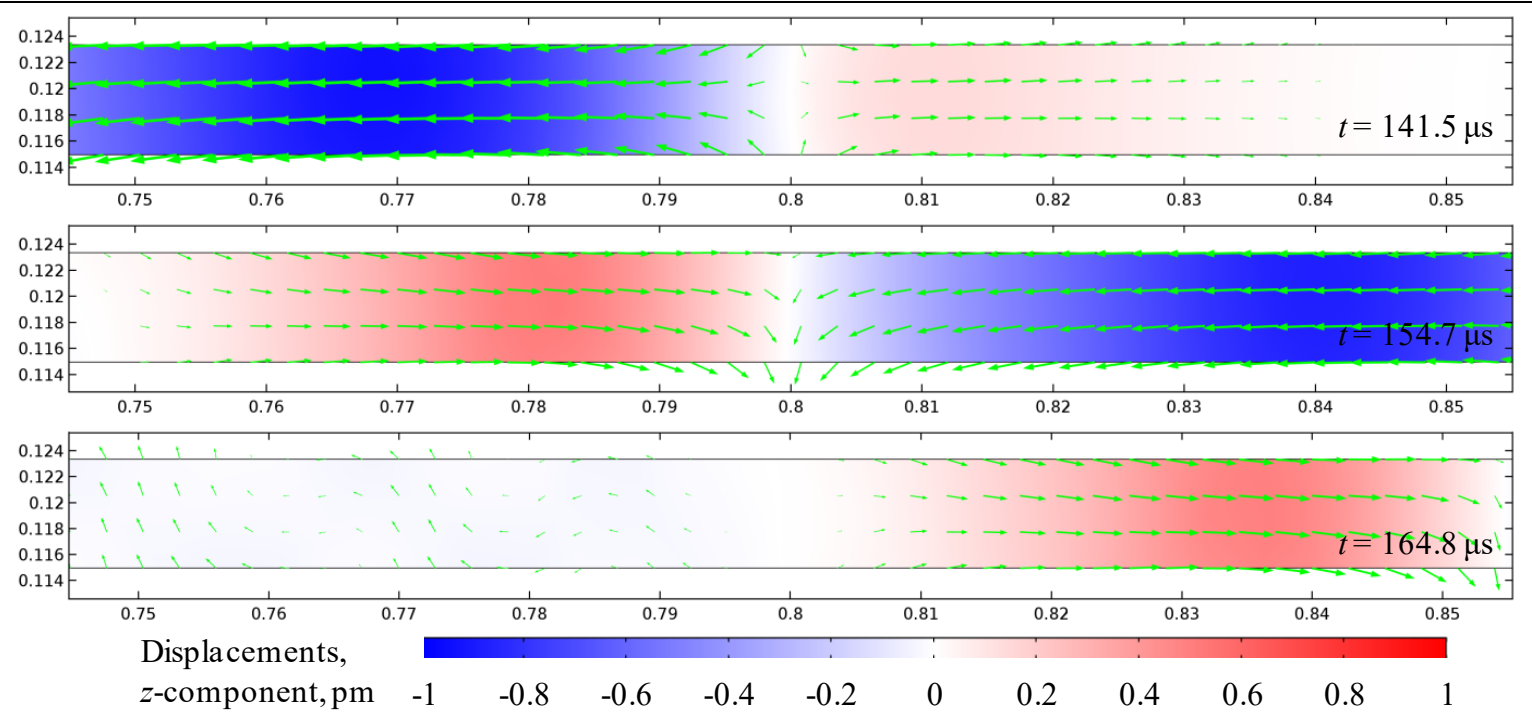

Figure 6. Longitudinal sectional distribution of displacements near the registration point at different points in time, $t=141.5 \mu \mathrm{s}$ (corresponds to the beginning of the pulse), $t=154.7 \mu \mathrm{s}$ (a half period of the pulse), $t=164.8 \mu \mathrm{s}$ (the whole period of the pulse): light wave graduation is used, the dark blue color corresponds to the maximum negative displacements, the dark red corresponds to the maximum positive displacements (approximately $50 \mathrm{pm}$ )

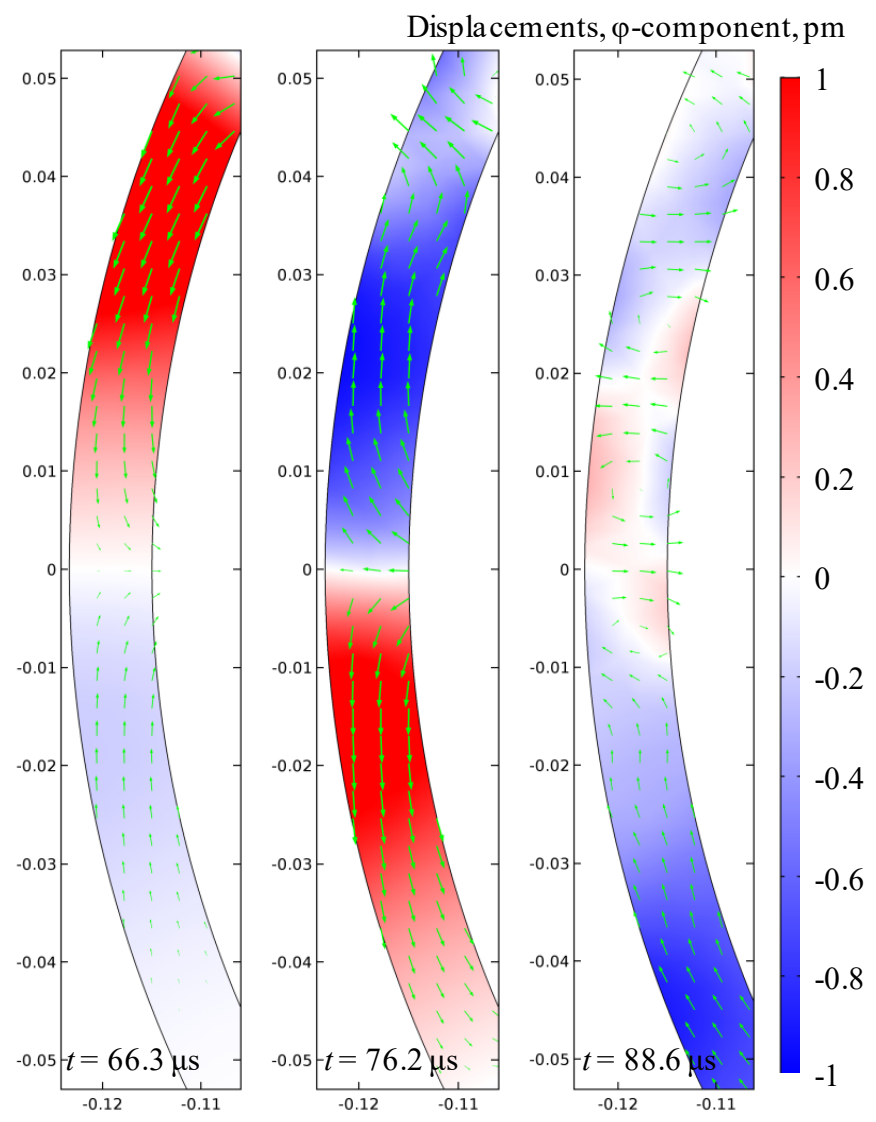

Figure 7. Cross sectional distribution of displacements near the left side of the pipe at different points in time, $t=66.3 \mu \mathrm{s}$ (corresponds to the beginning of the pulse), $t=76.2 \mu \mathrm{s}$ (a half period of the pulse), $t=88.6 \mu$ s (the whole period of the pulse): light wave graduation is used, the dark blue color corresponds to the maximum negative displacements, the dark red corresponds to the maximum positive displacements (approximately $50 \mathrm{pm}$ ) 


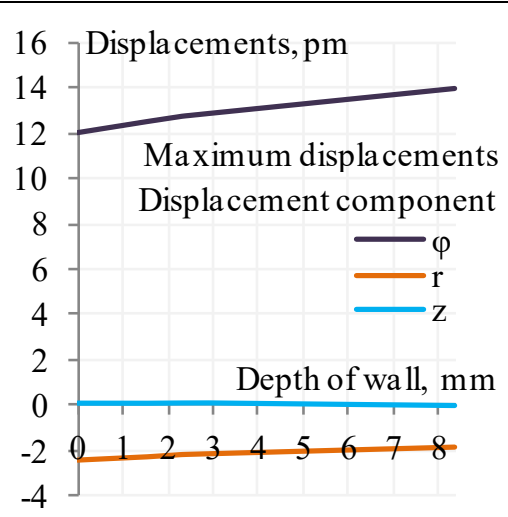

a

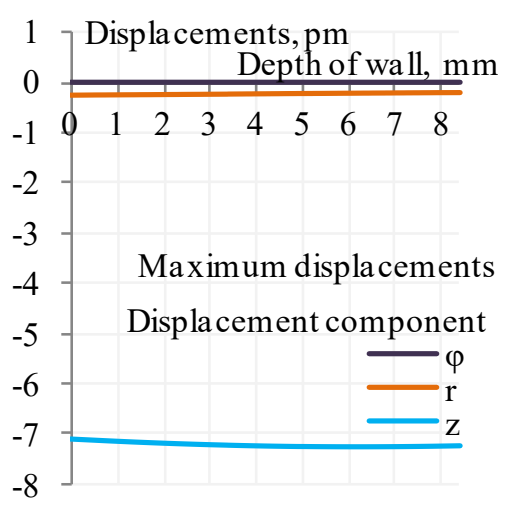

d

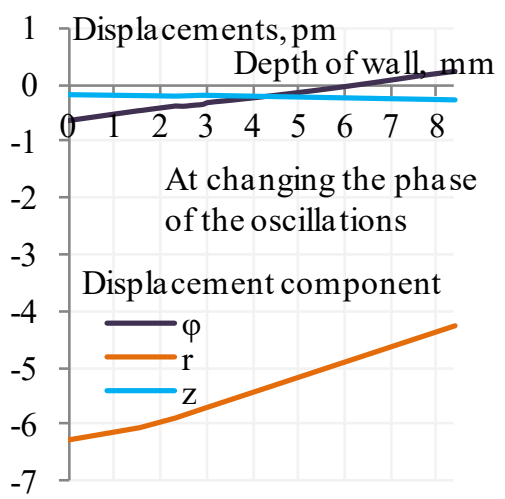

$\mathrm{b}$

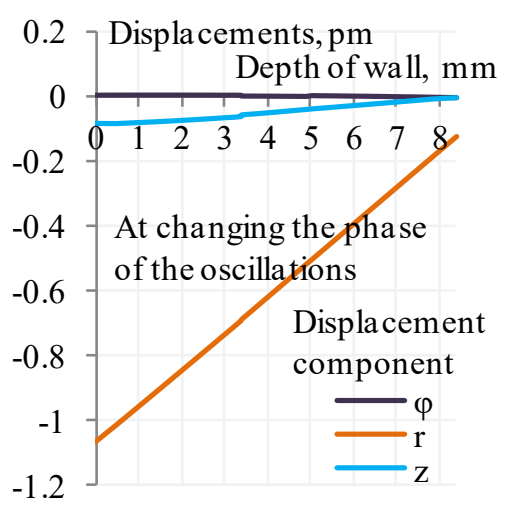

e

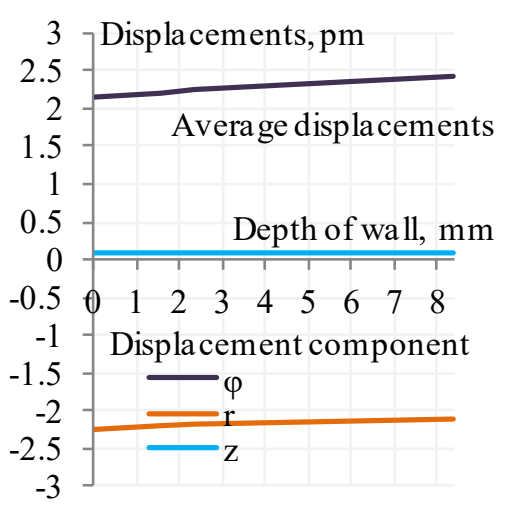

c

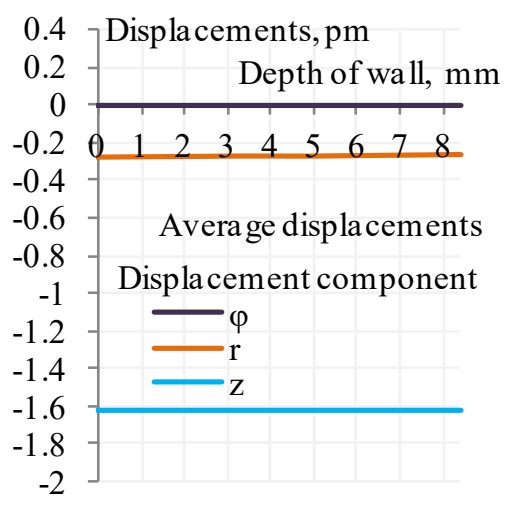

f

Figure 8. Displacement diagrams in cross section $(a, b, c)$ and longitudinal section $(d, e, f)$ at maximum displacements (a,d) at changing the phase of the oscillations $(b, e)$ and at average displacements $(\mathrm{c}, \mathrm{f})$

\section{EXPERIMENTAL SETUP}

To confirm the simulation results, an experiment was performed and conducted. The experimental setup is similar to that described in [35] and is shown in Figure 9. The setup includes a pipe, two low-frequency piezoelectric transducers with a dry point contact for studying the wave propagation velocity, a high-frequency piezoelectric transducer for thickness measurement, and a DIO-1000 ultrasonic flaw detector. The symmetric Lamb wave was excited at a frequency of $50 \mathrm{kHz}$ by a piezoelectric transducer with a dry point contact at a distance of $200 \mathrm{~mm}$ from the pipe end from the outer cylindrical surface of the pipe and was received by a second similar transducer at a distance of $600 \mathrm{~mm}$ from the excitation point at angles of deviation of the wave propagation path from the pipe generatrix $0-180$ degrees in increments of 1 degree. The wave was excited and received mainly due to shear stresses directed along its propagation and provided by the orientation of the transducers. Excitation was carried out on both sides of the pipe ends.

In addition to the wave propagation velocity, the pipe wall thickness was measured according to the scheme shown in Figure 9b. To do this, it is used a transducer at a frequency of $5 \mathrm{MHz}$, which was installed on the outer cylindrical surface of the pipe at 234 points with a step along the generatrix of $50 \mathrm{~mm}$ and an envelope of 20 degrees (approximately $43 \mathrm{~mm}$ ). For increased accuracy, the pipe wall thickness was calculated from the fifth bottom echo pulse. 


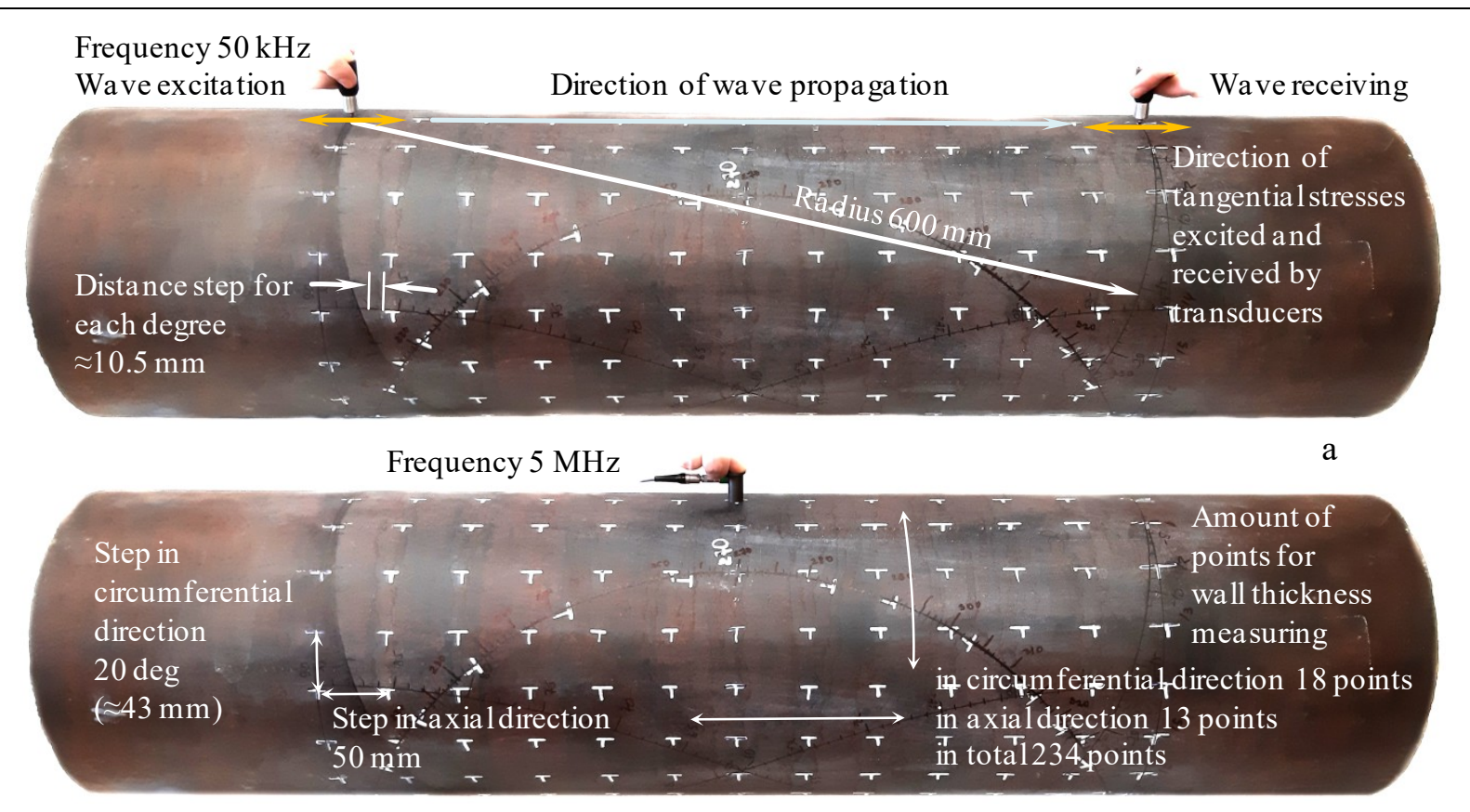

$\mathrm{b}$

Figure 9. The experimental setup: for measuring the propagation velocity of the symmetric Lamb wave (a), for measuring the wall thickness (b)

\section{RESULTS AND DISCUSSION}

The results of measuring the wall thickness of the pipe are presented in Figure 10. In the presented distribution there is a section of heterogeneity along the wall thickness, indicating the presence of a longitudinal weld. The remaining values have small deviations within 0.15 $\mathrm{mm}$ from the average value of the pipe wall thickness, which amounted to $8.43 \mathrm{~mm}$. The total measurement error of the pipe wall thickness was $0.02 \mathrm{~mm}$.

Figure 11 shows the dependences of the propagation velocity of the symmetric Lamb wave on the angle of deviation of the wave propagation path in the polar coordinate system. For clarity, the influence on the wave propagation velocity in the figures also shows maps of the distribution of the pipe wall thickness. The dependency graphs are characterized by an increase in values in the circumferential direction (90 and 270 degrees), reaching $5615 \mathrm{~m} / \mathrm{s}$, which is $250 \mathrm{~m} / \mathrm{s}$ more than the calculated theoretical velocity values without taking into account geometric anisotropy. In the direction along the generatrix, the average value of the velocity within 20 degrees does not differ from the theoretical one and is equal to the propagation velocity in the plate. Further, with an increase in the angle by 1 degree, the velocity increases by $2.5 \mathrm{~m} / \mathrm{s}$ to 80 degrees. Thus, the velocity of the symmetric Lamb wave varies from 5325 to $5615 \mathrm{~m} / \mathrm{s}$ with a total range of $290 \mathrm{~m} / \mathrm{s}$.

The spikes in the graph in velocity are related to the inaccurate arrangement of the transducer, the quality of the acoustic contact, the unevenness in the wall thickness and the heterogeneity of the properties of the pipe material. Taking these factors into account, the total velocity calculation error was $20 \mathrm{~m} / \mathrm{s}$.

In the range of angles of deviation of the wave propagation path from the generatrix of the pipe by 20 degrees, a maximum in wave propagation velocity is observed, which exceeds the average velocity by $20 \mathrm{~m} / \mathrm{s}$ and is associated with the presence of bulge in the studied section of the pipe. 


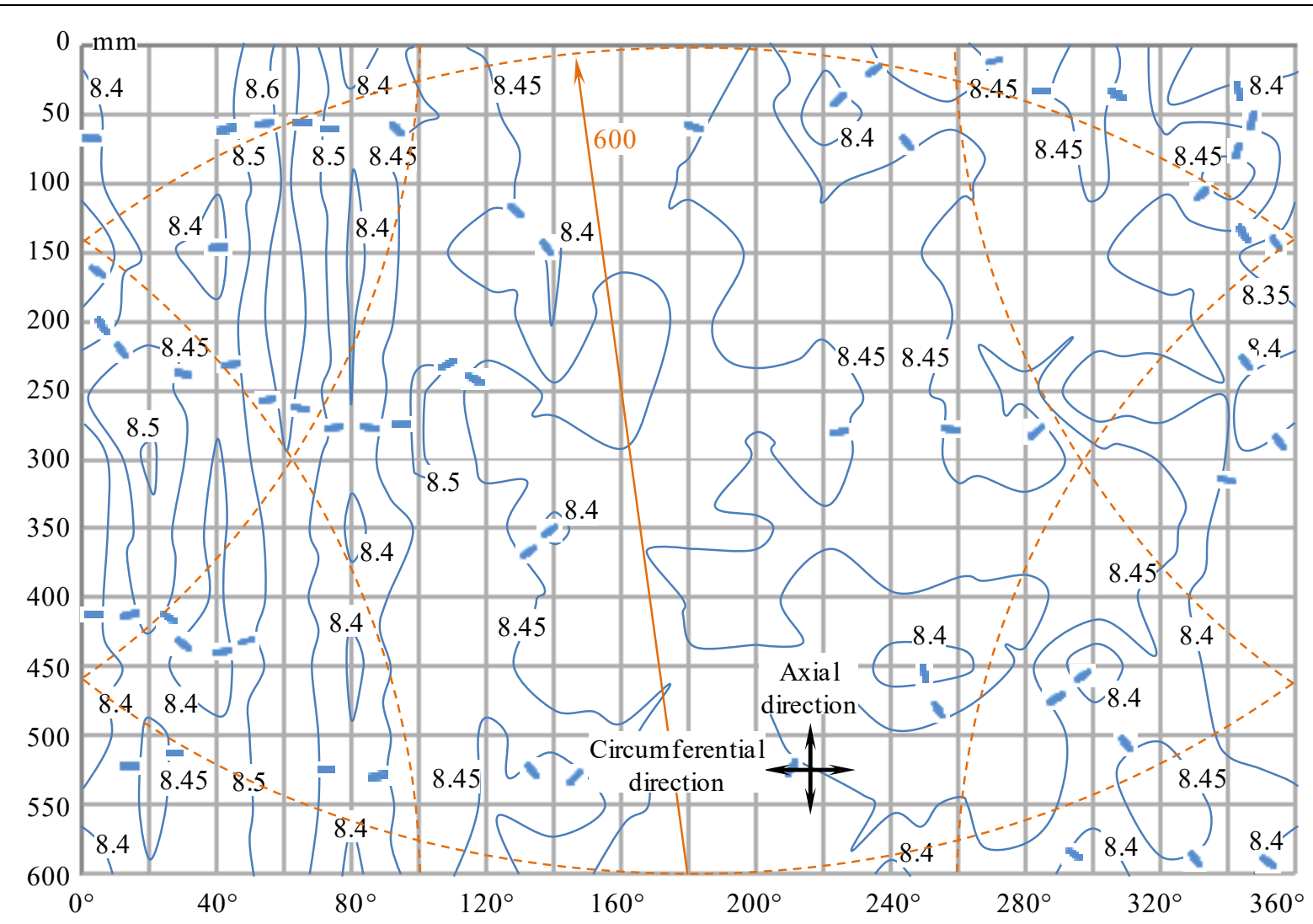

Figure 10. Results of thickness measurement: solid lines indicate the lines of the contour with the same value of the wall thickness; the dashed line corresponds to the location of the transducer for measuring the propagation velocity of the symmetric Lamb wave

\section{CONCLUSIONS}

Thus, according to the results of studies of the propagation of the symmetric Lamb wave in a hollow cylinder, the following conclusions can be drawn.

- The velocity of the wave depends on the direction of its propagation (the phenomenon of geometric dispersion): in the circumferential direction, the velocity is greater than in the direction along the generatrix and for a pipe with a diameter of $247 \mathrm{~mm}$, the velocity difference is $290 \mathrm{~m} / \mathrm{s}$.

- The pipe wall thickness affects the wave propagation velocity: the smaller the wall thickness, the lower the velocity.

- The ratio of the longitudinal displacement component to the vertical shear is greater, the closer the wave propagation path to the pipe generatrix, which can increase up to 5 times.

- Simulation results are in satisfactory agreement with experimental data.

The study results can be used to create and develop methods for monitoring the residual thickness of the pipe wall, taking into account the phenomenon of geometric dispersion in focusing algorithms, and analyzing and calculating the coordinates of a defect at guided wave testing. 


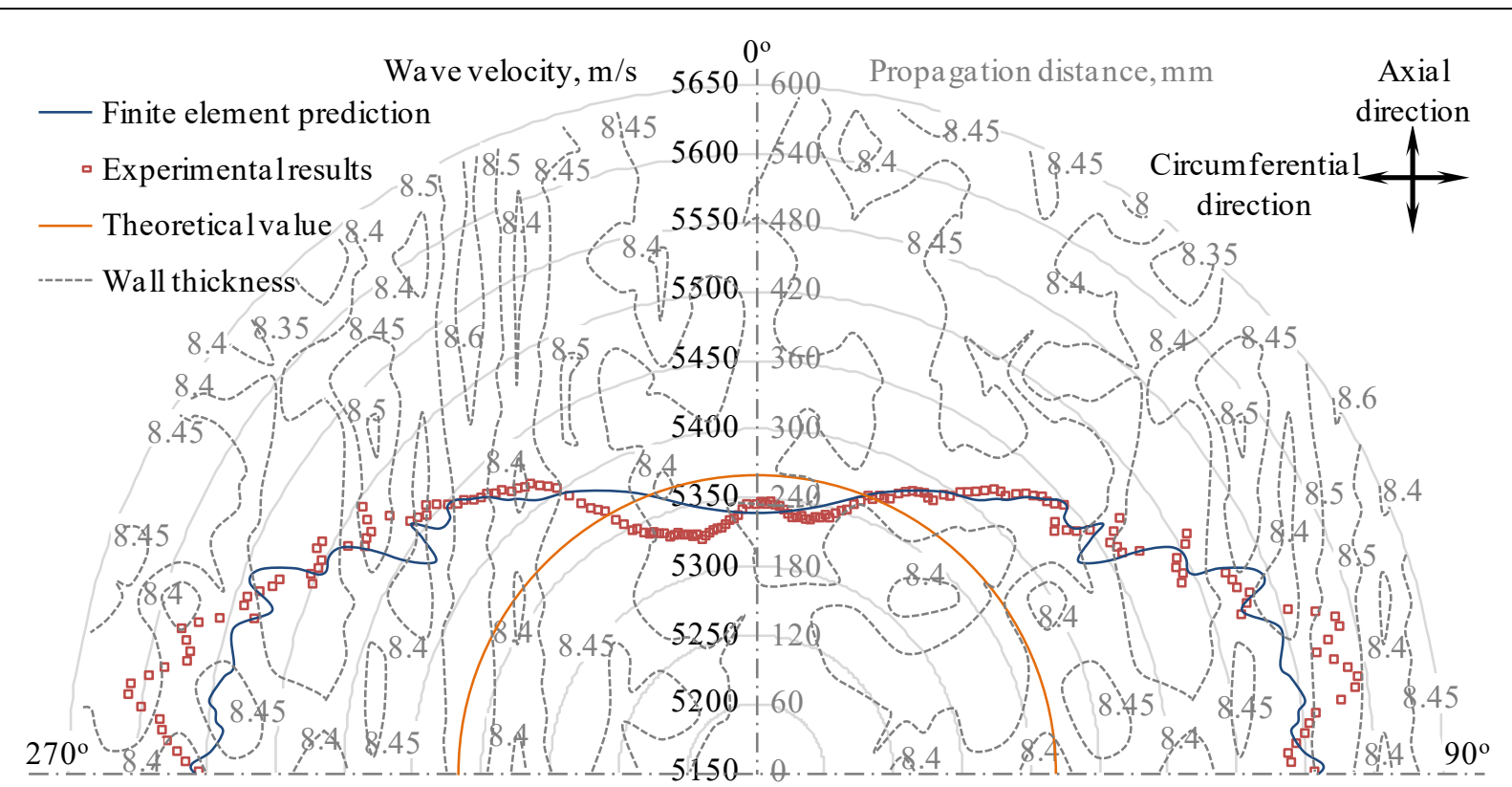

a

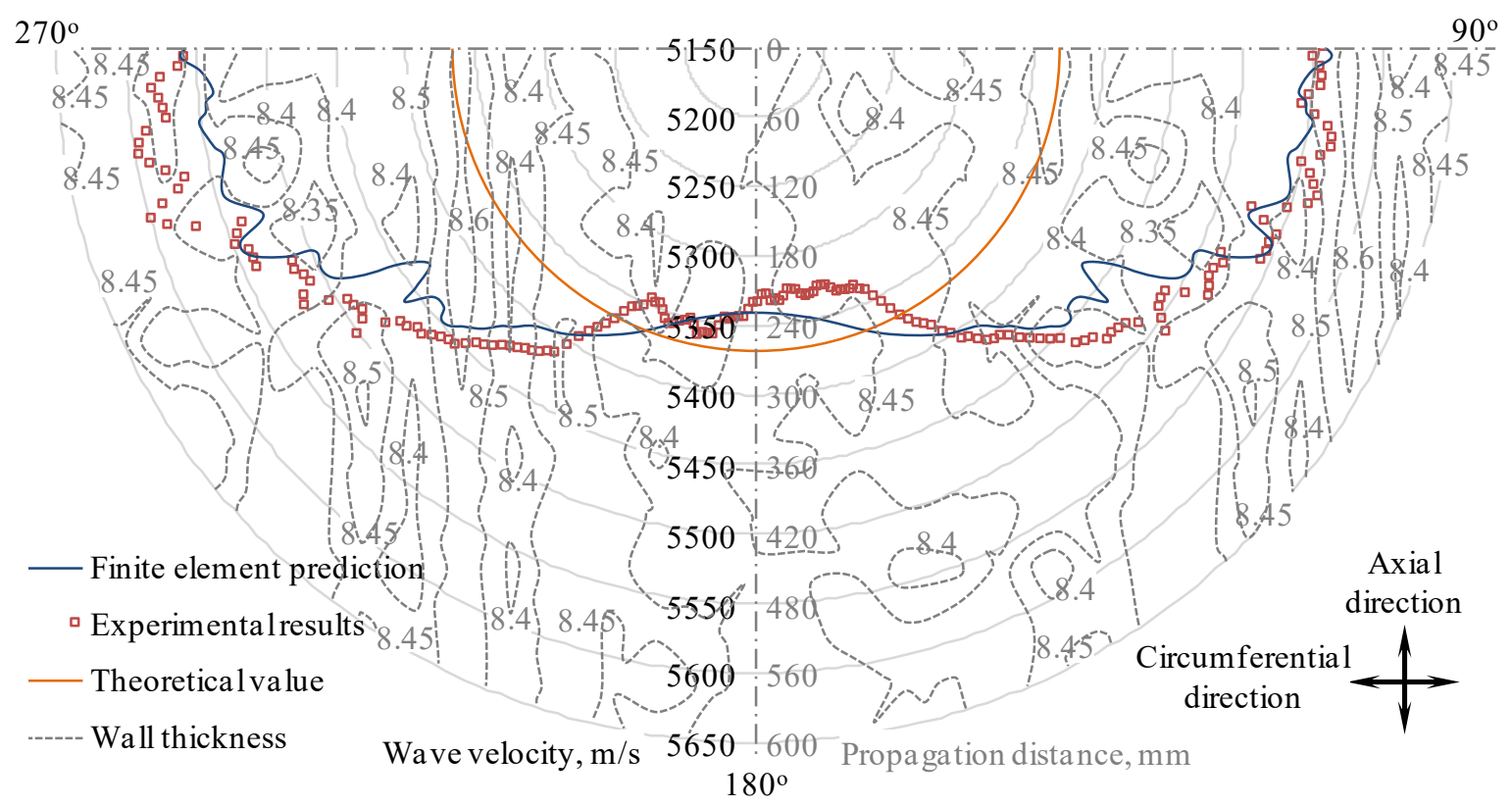

b

Figure 11. Dependence of symmetric Lamb wave on direction of the propagation in the hollow steel cylinder: left black scale (wave velocity) refers to experimental result, finite element prediction, and theoretical value; right gray scale (propagation distance) refers to wall thickness

\section{ACKNOWLEDGEMENTS}

This work was supported by the Russian Science Foundation (Project No. 18-79-10122) using Universal Scientific Unit "Information-measuring complex for evaluation acoustic properties of materials and products" (reg. No. 586308). 


\section{REFERENCES}

1. Zlobin, D. V., \& Muravieva, O. V. (2012). Development features of electromagnetic acoustic defectoscopy equipment for bar iron using rod waves. Bulletin of Kalashnikov ISTU, (4), 099-104. (in Russian).

2. Strizhak, V. A., Hasanov, R. R., \& Pryakhin, A. V. (2018). Features of excitation of an electromagnetic acoustic transducer under a waveguide method of testing. Bulletin of Kalashnikov ISTU, 21(2), 159-166. (in Russian). doi: 10.22213/2413-1172-2018-2-159-166

3. Muravyova, O. V., \& Murashov, S. A. (2011). Use of torsional waves for detection of operational defects in pump rods and tubing. Bulletin of Kalashnikov ISTU, (2), 149-154. (in Russian).

4. Strizhak, V. A., Pryakhin, A. V., Khasanov, R. R., \& Mkrtchyan, S. S. (2019). Flaw detection of composite rebar by acoustic wave guided technique. Bulletin of Kalashnikov ISTU, 22(1), 78-88. (in Russian). doi: 10.22213/2413-1172-2019-1-78-88

5. Myshkin, Y. V., \& Muravieva, O. V. (2017). The features of the guided wave excitation and propagation at testing of pipes. Journal of Physics: Conference Series, 881(1), 012019. doi: 10.1088/1742$6596 / 881 / 1 / 012019$

6. Evans, M., Lucas, A., \& Ingram, I. (2018). The inspection of level crossing rails using guided waves. Construction and Building Materials, 179, 614-618. doi: 10.1016/j.conbuildmat.2018.05.178

7. Wu, J., Tang, Z., Lü, F., \& Yang, K. (2018). Ultrasonic guided wave focusing in waveguides with constant irregular cross-sections. Ultrasonics, 89, 1-12. doi: 10.1016/j.ultras.2018.04.003

8. Myshkin, Y. V., \& Muravieva, O. V. (2016). Influence of the viscoelastic media properties on the lowest Lamb wave mode propagation in pipe. In: Instrumentation Engineering, Electronics and Telecommunications-2015 (pp. 152-156). Izhevsk, Russia: Publishing House of Kalashnikov ISTU.

9. Rose, J. L. (2014). Ultrasonic guided waves in solid media. Cambridge university press.

10. Jenot, F., Ouaftouh, M., Duquennoy, M., \& Ourak, M. (2001). Corrosion thickness gauging in plates using Lamb wave group velocity measurements. Measurement Science and Technology, 12(8), 1287-1293. doi: $10.1088 / 0957-0233 / 12 / 8 / 341$

11. Lowe, M. (1998). Characteristics of the reflection of Lamb waves from defects in plates and pipes. In: Thompson, D. O., Chimenti, D. E. (Eds.). Review of progress in quantitative nondestructive evaluation (pp. 113-120). Boston, USA: Springer. doi: 10.1007/978-1-4615-5339-7_14

12. Xu, H., Xu, C., Li, X., \& Wang, L. (2011). Study on single mode Lamb wave interaction with defect of plate by finite element model. Procedia Engineering, 15, 5067-5072. doi: 10.1016/j.proeng.2011.08.941

13. Nagy, P. B., Simonetti, F., \& Instanes, G. (2014). Corrosion and erosion monitoring in plates and pipes using constant group velocity Lamb wave inspection. Ultrasonics, 54(7), 1832-1841. doi: 10.1016/j.ultras.2014.01.017

14. Lowe, M. J. S., Alleyne, D. N., \& Cawley, P. (1998). The mode conversion of a guided wave by a partcircumferential notch in a pipe. Journal of Applied Mechanics, 65(3), 649-656. doi: 10.1115/1.2789107

15. Demma, A., Cawley, P., Lowe, M., \& Pavlakovic, B. (2005). The effect of bends on the propagation of guided waves in pipes. Journal of Pressure Vessel Technology, 127(3), 328-335. doi: 10.1115/1.1990211

16. Zhao, Y., Shen, Z., Lu, J., Ni, X., \& Cui, Y. (2012). A numerical study of the interaction of laser-generated circumferential wave with defect on hollow cylinder. Optics \& Laser Technology, 44(2), 407-411. doi: 10.1016/j.optlastec.2011.08.004

17. Pei, J., Yousuf, M. I., Degertekin, F. L., Honein, B. V., \& Khuri-Yakub, B. T. (1996). Lamb wave tomography and its application in pipe erosion/corrosion monitoring. Journal of Research in Nondestructive Evaluation, 8(4), 189-197.

18. Tapkov, K. A. (2018). Strain stress modeling of differential hardening rails. Intelligent Systems in Manufacturing (Intellekt. Sist. Proizv.), 16(2), 78-83. (in Russian). doi: 10.22213/2410-9304-2018-2-78-83

19. Murav’ev, V. V., Volkova, L. V., Platunov, A. V., Buldakova, I. V., \& Gushchina, L. V. (2018). Investigations of the structural and strain-stress state of the rails of current production by the acoustic elasticity method. Bulletin of Kalashnikov ISTU, 21(2), 13-23. (in Russian). doi: 10.22213/2413-1172-2018-2-13-23 
20. Rudd, K. E., Leonard, K. R., Bingham, J. P., \& Hinders, M. K. (2007). Simulation of guided waves in complex piping geometries using the elastodynamic finite integration technique. The Journal of the Acoustical Society of America, 121(3), 1449-1458. doi: 10.1121/1.2431335

21. Strizhak, V. A., Hasanov, R. R., \& Pryakhin, A. V. (2018). Features of excitation of an electromagnetic acoustic transducer under a waveguide method of testing. Bulletin of Kalashnikov ISTU, 21(2), 159-166. (in Russian). doi: 10.22213/2413-1172-2018-2-159-166

22. Nishino, H., Asano, T., Taniguchi, Y., Yoshida, K., Ogawa, H., Takahashi, M., \& Ogura, Y. (2011). Precise measurement of pipe wall thickness in noncontact manner using a circumferential Lamb wave generated and detected by a pair of air-coupled transducers. Japanese Journal of Applied Physics, 50(7S), 07HC10. doi: 10.1143/JJAP.50.07HC10

23. Nishino, H., \& Yoshida, K. (2006). Simple method of generating for circumferential shear horizontal waves in a pipe and their mode identifications. Acoustical Science and Technology, 27(6), 389-392. doi: 10.1250/ast.27.389

24. Leonard, K. R., \& Hinders, M. K. (2003). Guided wave helical ultrasonic tomography of pipes. The Journal of the Acoustical Society of America, 114(2), 767-774. doi: 10.1121/1.1593068

25. Matuszyk, P. J. (2017). Modeling of guided circumferential SH and Lamb-type waves in open waveguides with semi-analytical finite element and perfectly matched layer method. Journal of Sound and Vibration, 386, 295-310. doi: 10.1016/j.jsv.2016.09.019

26. Clough, M., Fleming, M., \& Dixon, S. (2017). Circumferential guided wave EMAT system for pipeline screening using shear horizontal ultrasound. NDT \& E International, 86, 20-27. doi: 10.1016/ j.ndteint.2016.11.010

27. Nishino, H., Yokoyama, R., Kondo, H., \& Yoshida, K. (2007). Generation of circumferential guided waves using a bulk shear wave sensor and their mode identification. Japanese Journal of Applied Physics, 46(7S), 4568. doi: 10.1143/JJAP.46.4568

28. Zhao, X., \& Rose, J. L. (2004). Guided circumferential shear horizontal waves in an isotropic hollow cylinder. The Journal of the Acoustical Society of America, 115(5), 1912-1916. doi: 10.1121/1.1691037

29. Sun, Z., Zhang, L., \& Rose, J. L. (2005). Flexural torsional guided wave mechanics and focusing in pipe. Journal of Pressure Vessel Technology, 127(4), 471-478. doi: 10.1115/1.2065587

30. Nishino, H., Takashina, S., Uchida, F., Takemoto, M., \& Ono, K. (2001). Modal analysis of hollow cylindrical guided waves and applications. Japanese Journal of Applied Physics, 40(1R), 364. doi: 10.1143/JJAP.40.364

31. Mineo, C., Cerniglia, D., \& Pantano, A. (2013). Surface waves on cylindrical solids: Numerical and experimental study. Ultrasonics, 53(4), 913-921. doi: 10.1016/j.ultras.2013.01.003

32. Park, M. H., Kim, I. S., \& Yoon, Y. K. (1996). Ultrasonic inspection of long steel pipes using Lamb waves. NDT \& E International, 29(1), 13-20. doi: 10.1016/0963-8695(95)00030-5

33. Li, J., \& Rose, J. L. (2001). Excitation and propagation of non-axisymmetric guided waves in a hollow cylinder. The Journal of the Acoustical Society of America, 109(2), 457-464. doi: 10.1121/1.1315290

34. Viktorov, I. A. (1967). Rayleigh and Lamb waves: Physical theory and applications. Springer US.

35. Myshkin, Yu. V., Murav'eva, O. V., Sannikova, Yu. O., \& Chukhlanceva, T. S. (2018). The propagation of horizontally polarized shear wave in the hollow cylinder. In: Instrumentation Engineering, Electronics and Telecommunications - 2018 (pp. 51-65). doi: 10.22213/2658-3658-2018-51-65 